\title{
The Effect Of Health Education On Bullying Knowledge Among Primary School Student
}

\author{
Desriani $^{1}$, Yeni Devita ${ }^{2}$ \\ 'STIKes Payung Negeri Pekanbaru \\ Email: Dedesdesriani@gmail.com \\ 2STIKes Payung Negeri Pekanbaru \\ Email: vitandesta@ymail.com
}

\section{Article Info}

Article history

Received date: 2019-11-16

Revised date: 2019-11-26

Accepted date: 2019-11-28

\begin{abstract}
Bullying becomes a serious and dangerous problem for students. The way to overcome bullying is by giving health education using discourse method. This research is aimed to find out the effect of health education using discourse method on students in teaching bullying awareness. This research was done 101 Public Elementary Pekanbaru in two days from $19^{\text {th }}-20^{\text {th }}$ June 2019. Quasi experimental design with pre-test and post-test was used as the research design of this research. Grade 3-5 students were used as the population. 117 of them were used as the samples. The samples were chosen by using total sampling. Furthermore, questionnaire about bullying were used as a tool to measure bullying awareness. The data were analyzed by using Wilcoxon test. From the result, it was obtained that the average grade before students were given health education using discourse method was 8.64, however, after students were given health education using method discourse, the average was 10.28 . The statistic test result shows $p$ value $=0,000(p<0,05)$ which means there is a significant effect of health education using discourse method on students in teaching bullying awareness.
\end{abstract}

Key Words : Bullying, Health Education, Discourse Method

\begin{abstract}
Abstrak
Bullying menjadi masalah serius dan sangat berbahaya pada usia sekolah. Cara untuk mengatasi bullying adalah dengan memberikan pendidikan kesehatan yaitu menggunakan metode ceramah. Penelitian ini bertujuan untuk mengetahui pengaruh pendidikan kesehatan metode ceramah terhadap pengetahuan bullying pada anak usia sekolah. Penelitian ini dilakukan di Sekolah Dasar Negeri 101 Pekanbaru selama 2 hari pada tanggal 19-20 juni 2019. Desain penelitian yang digunakan adalah quasi experiment dengan pre and post test without control. Populasi pada penelitian ini dari kelas 3-5 dengan sampel berjumlah 177 siswa dan menggunakan pengambilan sampel total sampling. Instrumen penelitian ini adalah kuesioner pengetahuan bullying yang dijadikan alat ukur untuk pengetahuan bullying. Analisis yng digunakan adalah uji Wilcoxon. Hasil penelitin didapatkan nili rat-rta pengetahuan sebelum diberikn pendidikn kesehatan metode ceramah sebanyak 8,64 , sedangkan setelah dilakukan pendidikan kesehatan sebanyak 10,28. Hasil uji statistic menunjukkan $p$ value $=0,000(p<0,05)$ yang berarti ada pengaruh yang bermakna dari pendidikan kesehatan metode ceramah terhadap pengetahuan bullying pada anak usia sekolah.
\end{abstract}

Kata Kunci : Bullying, Pendidikan Kesehatan, Metode Ceramah

\section{PENDAHULUAN}

Berdasarkan data dari United Nation International Childern's Emergency Fund, menunjukkan bahwa perilaku bullying di dunia menduduki angka yang tinggi, beberapa negara diantaranya ialah di 
Vietnam dengan jumlah $79 \%$, perilaku bullying di Nepal $79 \%$, perilaku bullying di Kamboja $73 \%$, dan perilaku bullying di Pakistan 43\%. Perilaku bullying di Jepang diantara jenis-jenis perundungan yang terjadi yang sering dilakukan oleh murid adalah umpatan, fitnah atau ejekan sebanyak $62,5 \%$ [1]. Komisi Perlindungan Anak Indonesia Jakarta mencatat 1.480 kasus pengaduan bullying di pendidikan. KPAI menemukan bullying di sekolah sebesar $87,6 \%$ dimana $(29.9 \%)$ bullying dilakukan oleh guru, $(42.1 \%)$ dilakukan oleh teman sekelas, dan $(28.0 \%)$ dilakukan oleh teman lain kelas [2]. Sebanyak 53,3\% perilaku bullying terjadi pada anak sekolah di Kote Pekanbaru, 52,8\% pernah mengalami bullying fisik, $51,8 \%$ pernah mengalami bullying verbal, dan $62,8 \%$ pernah mengalami bullying mental [3].

Faktor-faktor yang mempengaruhi perilaku bullying pada anak usia sekolah adalah faktor individu, faktor teman sebaya, faktor media, dan faktor sekolah [4]. Hasil penelitian menunjukkan bahwa ada hubungan antara umur, jenis kelamin, kelas, pekerjaan ibu, media kekerasan, perkelahian, dan makian dengan perilaku bullying pada anak usia sekolah [5]. Bully pada anak adalah masalah serius yang ada di seluruh negeri, hal ini sangat berbahaya bagi anak dalam jangka waktu panjang, anak-anak yang dibully dapat terhambat secara emosional dan social [6]. Kesulitan menyesuaikan diri dan lingkungan dapat berdampak pada sekolah anak, biasanya mereka ingin pindah sekolah atau keluar dari sekolah, dan sekalipun mereka masih di sekolah yang sama prestasi akademis anak akan terganggu, anak akan sering absen, terisolasi secara social [6].

Berdasarkan hasil study pendahuluan dengan metode penyebaran kuisioner multidimensional peer-victimization questioner bullying yang di lakukan oleh peneliti di SD Negeri 101 Pekanbaru pada tanggal 12 maret 2018 sebanyak 20 siswa di dapatkan bahwa, yang mengalami perilaku bully sebanyak 10 orang (50\%). Dimana pernah melakukan bullying fisik sebnayak (80\%) dan yang tidak melalukan sebanyak $(20 \%)$, pernah melakukan bullying verbal sebanyak (60\%) dan yang tidak melakukan sebanyak $(40 \%)$, pernah melakukan bullying mental sebanyak $(65 \%)$ dan yang tidak melakukan sebanyak (35\%). Dari hasil wawancara yang dilakukan penulis dengan salah satu guru di SD Negeri 101 Pekanbaru mengatakan bahwa siswa yang terkena bully siswa yang pendiam, yang memiliki kemampuan kurang seperti tidak bisa membaca, tidak bisa menulis, bahkan yang pintar pun sering di bully.

\section{METODE PENELITIAN}

Jenis penelitian ini merupakan penelitian kuantitatif, dengan pendekatan quasy experiment, dengan desain penelitian pre and post test without control [7]. Populasi dalam penelitian ini adalah seluruh siswa kelas 3,4 dan 5 di SDN 101 Pekanbaru. Jumlah populasi sebanyak 177 siswa. Sampel pada penelitian ini seluruh siswa kelas 3, 4 dan 5 di SDN 101 Pekanbaru sebanyak 177 siswa. Jadi total sampel pada penelitian ini sebanyak 177 siswa. Teknik pengambilan sampel pada penelitian ini menggunakan teknik total sampling.

Alat yang digunakan untuk mengukur pengetahuan bullying menggunakan kuisioner yang berjumlah 20 pertanyaan. Kuisioner yang digunakan terdiri dari data demografi (usia, jenis kelamin, dan kelas) dan pengetahuan bullying.

Kuesioner pengetahuan bullying ini telah diuji valid dan reabilitasnya pada tanggal 17 juni 2019 di SD negeri 70 Pekanbaru, dengan jumlah respoden 30 orang. Hasil uji validitas kuesioner didapatkan dari 20 kuesioner 13 yang valid karena nilai $r$ hitung $>$ dari $r$ tabel yaitu dengan rentang nilai $r$ hitung 0,481-0,886. Kemudian 7 pertanyaan tidak valid karena nilai $r$ hitung $<$ dari $r$ tabel dengan rentang nilai $r$ hitung $-0,17-0,334$. Hasil uji reliabelitas diperoleh $r$ alpha 0,934 , maka pernyataaan tersebut 
reliabel karena $r$ alpha $>r$ tabel yaitu $0,934.0,361$.

Analisa data yang digunakan analisa univariat dan bivariat dengan uji statistik uji Wilcoxon dengan derajat kemaknaan $\alpha=$ 0,05 .

\section{HASIL DAN PEMBAHASAN}

HASIL

\section{A. Hasil Analisis Univariat}

\section{Data Umum (Karakteristik Responden)}

\section{a. Usia}

Tabel 1 .

Distribusi Responden Berdasarkan Umur

\begin{tabular}{ccc}
\hline Umur & $\begin{array}{c}\text { Frekuensi } \\
(\mathbf{n})\end{array}$ & $\begin{array}{c}\text { Persentase } \\
(\%)\end{array}$ \\
\hline 8 tahun & 7 & 4,00 \\
\hline 9 tahun & 40 & 22,60 \\
\hline 10 tahun & 50 & 28,20 \\
\hline 11 tahun & 54 & 30,50 \\
\hline 12 tahun & 25 & 14,50 \\
\hline 13 tahun & 1 & 0,60 \\
\hline Total & 177 & 100 \\
\hline
\end{tabular}

Sumber : Analisis Data Primer, 2019

Berdasarkan tabel 1 didapatkan mayoritas umur responden adalah 11 tahun yaitu 54 orang $(30 \%)$ dan minoritas umur responden adalah 13 tahun yaitu 1 orang.

\section{b. Jenis Kelamin}

Tabel 2.

Distribusi Responden Berdasarkan Jenis Kelamin

\begin{tabular}{lcc}
\hline \multicolumn{1}{c}{ Jenis Kelamin } & $\begin{array}{c}\text { Frekuensi } \\
(\mathbf{n})\end{array}$ & $\begin{array}{c}\text { Persentase } \\
(\%)\end{array}$ \\
\hline Laki-laki & 91 & 51,40 \\
\hline Perempuan & 86 & 48,60 \\
\hline Total & 177 & 100 \\
\hline
\end{tabular}

Sumber : Analisis Data Primer, 2019

Berdasarkan tabel 2 didapatkan mayoritas responden berienis kelamin lakilaki yaitu sebanyak 91 orang $(51,40 \%)$ dan minoritas berjenis kelamin perempuan yaitu sebanyak 86 orang $(48,60 \%)$.
1. Data Khusus

a. Distribusi Pengetahuan Sebelum Pemberian Pendidikan Kesehatan Metode Ceramah Tabel 3.

Distribusi Pengetahuan Sebelum Diberiakan Pendidikan Kesehatan

Metode Ceramah di SDN 101 Pekanbaru 2019

\begin{tabular}{cccccc}
$\begin{array}{c}\text { Pengeta } \\
\text { huan }\end{array}$ & Mean & Median & SD & SE & $\begin{array}{c}\text { Min- } \\
\text { Max }\end{array}$ \\
\hline Sebelum & 8,64 & 9,00 & 2,28 & 0,17 & $\begin{array}{c}3- \\
13\end{array}$ \\
\hline
\end{tabular}

Sumber : Analisis Data Primer, 2019

Berdasarkan tabel 3 diketahui nilai mean pengetahuan sebelum diberikan pendidikan kesehatan adalah 8,64 dengan standar deviasi 2,28 . Nilai minimal 3 dan nilai maksimal 13

\section{b. Distribusi Pengetahuan Sesudah Pemberian Pendidikan Kesehatan Metode Ceramah}

Tabel 4

Distribusi Pengetahuan Sesudah Diberikan Pendidikan Kesehatan Metode Ceramah di SDN 101 Pekanbaru 2019

\begin{tabular}{cccccc}
\hline $\begin{array}{c}\text { Pengeta } \\
\text { huan }\end{array}$ & Mean & Median & SD & SE & $\begin{array}{c}\text { Min- } \\
\text { Max }\end{array}$ \\
\hline Sebelum & 10.28 & 11,00 & 2,07 & 0,15 & $3-13$ \\
\hline
\end{tabular}

Sumber : Analisis Data Primer, 2019

Berdasarkan tabel 4 diketahui nilai mean sesudah diberikan pendidikan kesehatan metode ceramah adalah 10,28 dengan standar deviasi 2,07. Nilai minimal 3 dan maksimal 13.

\section{B. Hasil Analisis Bivariat}

Tabel 5

Distribusi Pengetahuan Sebelum Dan Sesudah Diberikan Pendidikan Kesehatan Metode Ceramah

\begin{tabular}{|c|c|c|c|c|c|c|c|}
\hline $\begin{array}{c}\text { Vari } \\
\text { ab } \\
\text { el }\end{array}$ & $n$ & $\begin{array}{c}\text { Mea } \\
\mathrm{n}\end{array}$ & $\begin{array}{c}\text { Medi } \\
\text { an }\end{array}$ & SD & SE & $\begin{array}{l}\text { Min- } \\
\text { Max }\end{array}$ & $\begin{array}{c}P \\
\text { Val } \\
\text { ve }\end{array}$ \\
\hline $\begin{array}{l}\text { Sebe } \\
\text { lum }\end{array}$ & 177 & 8,64 & 9,00 & 2,28 & 0,17 & $3-13$ & $\begin{array}{l}0,0 \\
00\end{array}$ \\
\hline $\begin{array}{l}\text { Sesu } \\
\text { dah }\end{array}$ & 177 & $\begin{array}{c}10,2 \\
8\end{array}$ & $\begin{array}{c}11,0 \\
0\end{array}$ & 2,07 & 0,15 & $3-13$ & \\
\hline
\end{tabular}


Berdasarkan tabel 5 didapatkan nilai mean pengetahuan sebelum diberikan pendidikan kesehatan metode ceramah adalah 8.64 dengan standar deviasi 2,28. Nilai minimal pengetahuan sebelum diberikan perlakuan adalah 3 dan nilai maksimal 13. Sedangkan nilai mean setelah diberikan pendidikan kesehatan metode ceramah adalah 10,28 dengan standar deviasi 2,07. Nilai minimal pengetahuan setelah diberikan perlakuan adalah 3 dan nilai maksimalnya adalah 13. Berdasarkan tabel diatas diketahui terjadi peningkatan pengetahuan sebelum dan sesudah diberikan pendidikan kesehatan metode ceramah diperoleh mean sebelum diberikan pendidikan kesehatan adalah 8,64 dan median sesudah diberikan pendidikan kesehatan metode ceramah adalah 10,28 . Hasil uji statistik didapatkan $\mathrm{p}$ value $0,000<(0,05)$ yang berarti Ho ditolak. Hal ini menunjukkan ada pengaruh yang bermakna dari pemberian pendidikan kesehatan metode ceramah terhadap pengetahuan bullying pada anak usia sekolah.

\section{PEMBAHASAN}

\section{A. Interpretasi dan Diskusi Hasil}

\section{Analisis Univariat}

a. Umur

Berdasarkan uji statistik dapat dilihat bahwa mayoritas umur anak adalah 11 tahun sebanyak 54 orang (30,5\%). Desmita, (2010) mengatakan bahwa pada usia ini anak sudah dapat mengembangkan pikiran logisnya, dimana dalam upaya memahami alam sekitarnya, anak tidak lagi mengandalkan informasi yang bersumber dari alam pancaindra, karena pada saat ini anak mulai mempunyai kemampuan untuk membedakan apa yang tampak oleh mata dengan kenyataan sesungguhnya, pada masa ini daya fikir anak berkembang kearah yang lebih konkrit, rasional dan objektif.

Hal ini sejalan dengan penelitian yang dilakukan oleh Solikhah, (2015) yang menjelaskan bahwa pada masa ini anak sudah dapat memahami bagaimana cara untuk menilai tentang pengetahuan bullying. Sandy, (2012) dalam penelitiannya menjelaskan bahwa pada usia 6-12 tahun perkembangan psikososial anak berada pada tahap industri versus inferioritas, hal ini dapat meningkatkan kerentangan anak pada kejadian bullying karena pada masa ini anak sudah berinteraksi dengan teman sebaya dan lingkungan sekitarnya. Anak mulai berinteraksi dan akan berusaha mencapai kompetensi, Kegagalan dan keberhasilan dalam mencapai kompetensi di sekolah dapat memicu terjadinya perilaku bullying baik sebagai pelaku maupun korban.

Menurut asumsi peneliti, anak usia sekolah pada usia 11 tahun sudah mampu berinteraksi dengan baik dan sudah mampu memahami apa yang disampaikan oleh orang lain dan lingkungannya. Pada usia ini anak sudah dapat berinteraksi dengan teman sebayanya dan pada tahap ini anak mulai bersaing dalam kegiatan akademik maupun non akademik sehingga timbul keinginan tidak mau gagal. Kegagalan yang dialami anak dalam mencapai keinginannya dapat menjadi pemicu untuk melakukan tindakan bullying.

b. Jenis Kelamin

Berdasarkan uji statistik dapat dilihat bahwa mayoritas anak di SDN 101 Pekanbaru adalah lakilaki sebanyak 91 orang $(51,4 \%)$ sedangkan perempuan 66 orang $(46,6 \%)$. Populasi antara laki-laki dan perempuan memang 
menunjukkan lebih banyak laki-laki, sesuai data yang diperoleh menunjukkan laki-laki 355,13 dan perempuan 324,99 ((Pusat Data Dan Statistik Pendidikan Dan Kebudayaan, 2018). Maka hal ini sejalan dengan penelitian peneliti, didapatkan laki-laki menjadi populasi terbanyak. Perbedaan jenis kelamin mempengaruhi cara pandang individu terhadap dirinya. Anak perempuan sangat sensitif dengan kemampuan dirinya dan peka terhadap penilaian orang lain dibandingkan anak laki-laki ${ }^{[12] .}$

Hal ini sejalan dengan penelitian yang dilakukan oleh Dewi, (2014) yang memaparkan bahwa potensi anak laki-laki untuk terlibat dalam kejadian bullying lebih besar dibandingkan dengan anak perempuan. Penelition yang dilakukan oleh Sugmalestari, (2016) memaparkan bahwa anak laki-laki terlibat dalam kejadian bullying, anak laki-laki lebih sering bergaul secara fisik sedangkan anak perempuan cenderung berkumpul dan bercakap-cakap. Pada tahap ini, mulai muncul perkembangan identitas remaja untuk berkelompok dan menunjukkan tanda-tanda konformitas (sikap penyesuaian diri seseorang untuk mengikuti kaidahkaidah atau nilai-nilai yang sudah ada).

Saraswati (2015) memaparkan perbedaan anak laki-laki yaitu tingkat agresivitasnya, anak lakilaki cenderung akan lebih agresif daripada akan perempuan

Menurut asumsi peneliti jenis kelamin laki-laki lebih mudah memahami karena laki-laki lebih mengembangkan pemikiran logisnya dari pada perempuan dalam peningkatan pengetahuan. Pada dasarnya anak laki-laki memiliki sifat kasar dibandingkan perempuan, hal ini dapat terlihat ketika anak laki-laki bermain. Lelaki lebih sering melakukan tindakan kekerasan seperti medorong atau berkata kasar sehingga memicu terjadinya perilaku bullying.

\section{Analisis Bivariat}

Hasil penelitian yang dilakukan pada anak usia sekolah pada sekolah SD negeri 101 pekanbaru didapatkan nilai rata-rata pengetahuan sebelum diberikan pendidikan kesehatan metode ceramah adalah 8,64 dan sesudah diberikan pendidikan kesehatan metode ceramah adalah 10,28. Berdasarkan hasil uji Wilcoxon diperoleh $p$ value $=0,000 \leq$ alpha $(p$ value $=<0,05)$. Hal ini berarti ada pengeruh pemberian pendidikan kesehatan metode ceramah terhadap pengetahuan bullying pada anak usia sekolah. Perubahan pengetahuan merupakan proses belajar, yang akan efektif apabila stimulus yang diberikan sesuai dengan kebutuhan indidvidu Menurut Saraswati et al., (2018). Cara mengatasi bullying yaitu dengan cara mengubah dan mendidik siswa, membangun jejaring komunikasi dengan para orang tua, mendeklarasikan antibullying yang melibatkan peran aktif semua unsur sekolah dari para guru, siswa, karyawan, dan orang tua. Pemberian pemahaman bullying yang tepat untuk guru, karyawan, orang tua dan siswa salah satunya melalui pendidikan kesehatan. Pendidikan kesehatan merupakan salah satu faktor yang mempengaruhi pengetahuan, sehingga terjadi penyampaian informasi. Metode pendidikan kesehatan salah satu nya menggunakan metode ceramah. Metode ceramah adalah memberiakn sejumlah penjelasan kepada sejumlah siswa yang umumnya mengikuti secara pasif. Tujuan metode ceramah adalah menyampaikan 
informasi yang sangat luas agar dapat diekspresikan ke dalam proses kognitif, afektif, dan perilaku [16].

Pendidikan kesehatan metode ceramah mampu meningkatkan pengetahuan yang awalnya siswa memiliki pengetahuan kurang setelah diberikan intervensi siswa memiliki pengetahuan cukup. Pengetahuan yang ada pada seseorang diterima melalui indra dan sebagian besar pengetahuan manusia diperoleh dari indra mata dan telinga [17].

Hasil penelitian ini sejalan dengan penelitian yang dilakukan oleh Lubis et al., (2013) yaitu tentang "pengaruh penyuluhan dengan metode ceramah dan diskusi terhadap peningkatan pengetahuan dan sikap anak tentang perilaku hidup bersih dan sehat (PHBS) di sekolah dasar negeri 065014 kelurahan Namogajah kecamatan Medan Tuntungan" yang memaparkan bahwa penyuluhan metode ceramah memberikan pengaruh dalam meningkatkan pengetahuan tentang perilaku hidup bersih dan sehat (PHBS) pemberian informasi guna meningkat pengetahuan sehingga timbul kesadaran yang pada akhirnya anak akan berperilaku sesuai dengan pengetahuannya.

Penelitian ini juga sejalan dengan penelitian yang dilakukan oleh Lestari, Hidayati, \& Abadiyah (2019) yaitu tentang "Gema Suling Gerakan Masyarakat Sekolah Tanggap Bullying dalam Upaya Pencegahan Bullying Pada Anak Usia Sekolah" yang memaparkan bahwa edukasi metode ceramah memberikan pengaruh dalam meningkatkan pengetahuan terkait bullying pemberian edukasi ini sangat bermanfaat bagi siswa untuk mengidentifikasi kejadian bullying.

Menurut asumsi peneliti pendidikan kesehatan metode ceramah efektif dalam meningkatkan pengetahuan bullying. bullying merupakan tindakan yang berdampak buruk pada psikososial anak, sedangkan metode cermah adalah kegiatan menyampaikan informasi kepada individu yang mampu memberikan perubahan perilaku dan sikap siswa, sehingga Pemberian pendidikan kesehatan pada usia dini dapat mencegah terjadinya perilaku bullying pada anak sekolah dan juga memberikan pengetahuan kepada mereka yang melakukan bullying agar mereka tidak lagi melakukan perilaku bullying.

\section{SIMPULAN}

Berdasarkan hasil penelitian bahwa mayoritas usia anak di SD negeri 101 pekanbaru adalah 11 tahun dan mayoritas jenis kelamin laki-laki. Terdapat perbedaan pengetahuan sebelum dan sesudah diberikan pendidikan kesehatan metode ceramah. Hasil penelitian menunjukkan bahwa pendidikan kesehatan metode ceramah efektif dalam meningkatkan pengetahuan bullying pada anak usia sekolah.

Hasil dari penelitian ini dapat dijadikan sebagai acuan atau referensi dan diharapkan ada kelanjutan penelitian yang berkaitan dengan bullying dan mengikutsertakan variabel-variabel lain seperti menggunakan metode video dalam meningkatkan pengetahuan bullying pada anak usia sekolah.

\section{UCAPAN TERIMA KASIH}

Penulis mengucapkan terimakasih kepada Kepada STIKes Payung Negeri yang telah membantu dalam penyelesaian penelitian ini, dan ucapan terimakasih kepada kepala sekolah dasar negeri yang terlibat dalam penelitian ini, dan tentu saja siswa/i sekolah dasar negeri yang terlibat. Menyenangkan dapat bertemu dengan banyak responden pada penelitian ini. 


\section{REFERENSI}

[1] UNICEF, "Kekerasan Pada Anak: Kini Saatnya Bertindak," 2016.

[2] KPAl, "Kekerasan Anak di Sekolah Sangat Memprihatinkan," 2018.

[3] Y. Devita and F. Dyna, "Bullying on Elementary School Students," vol. 2019, no. 1, pp. 87-93, 2019.

[4] S. Sufriani and E. P. Sari, "Faktor yang Mempengaruhi Bullying pada Anak Usia Sekolah di Sekolah Dasar Kecamatan Syiah Kuala Banda Aceh," Idea Nurs. J., vol. 8, no. 3, 2017.

[5] Y. Devita and F. Dyna, "Analisis hubungan karakteristik anak dan lingkungan keluarga dengan perilaku bullying," Healthc. J. Kesehat., vol. 7, no. 2, pp. 15-21, 2018.

[6] S. Sucipto, "Bullying dan Upaya Meminimalisasikannya,"

Psikopedagogia J. Bimbing. dan Konseling, vol. 1, no. 1, 2016.

[7] kelana kusuma Dharma, Metodologi Penelitian Keperawatan, Edisi revi. Jakarta: Trans Info Media, 2015.

[8] Desmita, Psikologi Perkembangan. Bandung: PT. Remaja Rosdakaya, 2010.

[9] D. E. Solikhah, "Pengaruh Buku Saku Gizi Terhadap Tingkat Pengetahuan Gizi Pada Anak Kelas 5 Muhammadiyah Dadapan Desa Wonokerto Kecamatan Turi Kabupaten Sleman Yogyakarta," vol. 2015, 2015.

[10] W. Sandy, "Tingkat pengetahuan tentang keselamatan pada siswa sekolah dasar," 2012.

[1 1] P.D. D. S. P. D. Kebudayaan, "Jumlah Siswa Menurut Jenis Kelamin dan Status Sekolah Tiap Provinsi," 2018.

[12] D. Fitri and N. Aini, "Self Esteem Pada Anak Usia Sekolah Dasar Untuk Pencegahan Kasus Bullying," J. Pemikir. dan Pengemb. SD, vol. 6, no. April, pp. 36-46, 2018.
D. A. P. I. S. Dewi, "Gambaran

Kejadian dan Karakteristik Bullying Pada Anak Usia Sekolah Dasar Wilayah Puskesmas I Pekutatan Kabupaten Jembrana Bali 2014," vol. 8, no. 1, pp. 1-9, 2014.

[14] A. N. Sugmalestari, "Hubungan Jenis Kelamin Dengan Perilaku Bullying pada Anak Usia Sekolah di SD Muhammadiyah Mlangi Gamping Sleman Yogyakarta," pp. 1-4, 2016.

[15] E. Saraswati, "Perbedaan Hasil Belajar Siswa Laki-Laki dan Perempuan Dalam Mata Pelajaran Matematika Kelas III Semester 2 Materi Sudut dan Pecahan di SD negeri Se-Desa Caturhario, Kecamatan Sleman Kabupaten Sleman," 2015.

[16] Y. Saraswati, T. Suprihatiningsih, and S. Pranowo, "Pengaruh Pendidikan Kesehatan Tentang Bullying Dengan Metode Cermah Menggunakan Leaflet Dan LCD Terhadap Sikap Bullying Pelajar SMPN 4 Cilacap," Pros. Semin. Nas. dan Disem. Peneltitian Kesehat., no. April, pp. 125-128, 2018.

[17] Notoatmodjo, Promosi Kesehatan Teori dan Aplikasinya. Jakarta: Rineka Cipta, 2010.

[18] Z. S. A. Lubis, N. L. Lubis, and E. Syahrial, "Pengaruh Penyuluhan Dengan Metode Ceramah Dan Diskusi Terhadap Peningkatan Pengetahuan Dan Sikap Anak Tentang Phbs Di Sekolah Dasar Negeri $065014 \quad$ Kelurahan Namogajah Kecamatan Medan Tuntungan Tahun 2013," 2013.

[19] N. D. Lestari, L. N. Hidayati, and S. S. Abadiyah, "' Gema Suling ' Gerakan Masyarakat Sekolah Tanggap Bullying dalam Upaya Pencegahan Bullying pada Anak Usia Sekolah," vol. 8, no. 1, pp. 1-4, 2019. 